\title{
Recent Development of Graphene-Based Materials for Cathode Application in Lithium Batteries: A Review and Outlook
}

\author{
Yi Lu ${ }^{1,2,3, *}$, Fan Yang ${ }^{1}$, Geoff G.X. Wang ${ }^{2}$, Tianyu Zhang $^{1}$, Peng Wang ${ }^{l}$ \\ ${ }^{1}$ School of Resource, Environment and Safety Engineering, Hunan University of Science and \\ Technology, Xiangtan, Hunan 411201 \\ ${ }^{2}$ School of Chemical Engineering, University of Queensland, Brisbane, QLD 4072, Australia \\ ${ }^{3}$ Work Safety Key Lab on Prevention and Control of Gas and Roof Disasters for Southern Coal Mines, \\ Hunan University of Science and Technology, Xiangtan, Hunan 411201 \\ *E-mail: luyihnust@163.com
}

doi: $1020964 / 2019.07 .50$

Received: 2 April 2019 / Accepted: 5 May 2019 / Published: 10 June 2019

\begin{abstract}
Graphene composites have great potential in the field of lithium ion batteries due to their high specific surface area, high specific capacity, excellent electrical conductivity and remarkable chemical stability. In cathode materials, graphene can not only form a conductive network to improve the conductivity of composite materials but also buffer the volume effect that occurs during charging and discharging processes, improving the rate performance and cycle life of the material. In addition, it can theoretically be used to design large capacity and high stability lithium-ion batteries. Therefore, the preparation of graphene composites with different compositions and structures is a very important subject. Researchers have prepared graphene composites with different compositions and structures by various methods in recent years, and the results of these studies are summarized in this review.
\end{abstract}

Keywords: lithium ion battery; Cathode material; Review; Electrode modification; Energy material

\section{$\underline{\text { FULL TEXT }}$}

(C) 2019 The Authors. Published by ESG (www.electrochemsci.org). This article is an open access article distributed under the terms and conditions of the Creative Commons Attribution license (http://creativecommons.org/licenses/by/4.0/). 